\title{
A Study on the Innovation and Development of Strategic Emerging Industrial Clusters
}

\author{
Yunyang $\mathrm{Nie}^{1, \mathrm{a}}$ \\ ${ }^{1}$ University of Chinese Academy of Sciences, Beijing City, 100049, China \\ ${ }^{\mathrm{a}}$ email
}

Keywords: Strategic emerging industries; Industrial clusters; Innovation and development; Path; Model

\begin{abstract}
With the rapid development of China's economy, the development of strategic emerging industrial clusters has been rapidly promoted in many major regions of China, and this model has achieved obvious economic and social benefits. However, with the expansion of the total, there are also some problems - the scale of the industry is not large, the degree of cluster is not high, and the policy support is not in place. Based on the author's learning and practical experience, this paper mainly analyzed the cluster development path of strategic emerging industries, and then proposed the carrier and structure optimization of strategic emerging industrial clusters development.
\end{abstract}

\section{Introduction}

The State Council has issued the "13th Five-Year" National Strategic Emerging Industries Development Planning on November 29, 2016, in which has put forward that strategic emerging industries represent the direction of a new round of technological revolution and industrial change, and it is the key area to develop new energy and gain new competitive advantage in the future. As a matter of fact, cluster development is a scientific path for the transformation and upgrading of strategic emerging industries in China,the technology and capital of strategic emerging industrial clusters will be gradually developed through the form of cluster. Therefore, studying strategic emerging industries development path and putting forward a more mature path and its development strategy has a certain positive impact on the upgrading of the industry.

\section{Innovative Development Path of Strategic Emerging Industrial Clusters}

The development path of value chain as a medium. The value chain is a basic concept of economic activities, which are involved in many problems in economics. There are value chains in business contacts among different enterprises, even in the same department, business contacts and capital exchanges between departments can also produce value chains. In the development path of the value chain, the strategic emerging industrial clusters can develop together, and the essence of which is the pursuit of profit. As the maximization of profit is the eternal theme of the enterprise, the path is the most efficient, the most stable and the most fundamental way for the development of strategic emerging industrial clusters. In the value chain of the invisible hand under the command of strategic emerging industrial clusters always do and stick to order. A variety of resources and abilities coordinate effectively with other enterprises to develop together.

The development path of knowledge chain as a medium. Science and technology are the primary productive forces, but science and technology derive from knowledge. Therefore, with the help of knowledge quantity as a development path, we can upgrade the traditional industrial 
cluster into an intelligent and advanced industrial cluster. Through the exchange of knowledge, different enterprises can get more valuable information and develop faster under the guidance of the state policy. Enterprises can seize other party's aims, intentions and capabilities accurately, and then the cultural industry cluster will develop into a common carrier of knowledge and culture, which is also one of the best visions for the development of strategic emerging industries.

The development path of Internet of things as a medium. Internet of things connect any items with the Internet for information exchange and communication in accordance with the consistent agreement, which through radio frequency identification (RFID), infrared sensors, GPS, laser scanners and other information sensing equipment so as to realize a network with intelligent identification, positioning, tracking, monitoring and management. If the Internet of things dock with knowledge network, it can be integrated into a huge network of material resources positioning, monitoring, sharing and exchange platform. Thus, the strategic emerging industrial clusters are integrated into a visual management of the material resources. In the resource pool, as long as there is demand for material resources with regardless of ownership, it can use resources in a certain contract and transaction. Therefore, the development path of the Internet of things integrates the material resources of the strategic emerging industries with different strategies through the Internet of things, so that it can realize a model of resource sharing. In this model, the utilization of resources can be maximized, and the ability of value improving of resources will be greatly enhanced.

\section{The Carrier of Strategic Emerging Industrial Clusters and the Optimization of Industrial Structure Upgrading}

The carrier of strategic emerging industry cluster development. The formation of strategic emerging industrial clusters is influenced by many factors, such as resources, market, population, science,technology and economic system. Among these factors, technology and economy are more prominent. The essence of strategic emerging industrial clusters is to integrate the scientific and technological resources with economic resources in a certain category, and then to form a good carrier. In recent years, science and technology park is a carrier of professional management because of the development of science and technology and the continuous supply of talents. In the science and technology park, the enterprise will create conditions for the creation of a new enterprise through incubation projects and asset classification. Industrial Park has gathered new and high technology, and the existence of such carriers is to promote the innovation of related industries, enhance the competitiveness of the industry in the market, finally increasing the wealth of the Industrial Park. As the representative of the science and technology park in recent years, Silicon Valley has become the world's leading knowledge economy. It can be seen that the development of mature, export-oriented industrial clusters have become the main force of economic growth. In this regard, Zhongguancun, Wuhan Optics Valley and some other industrial parks in the strategic emerging industrial cluster play a great power, provide intellectual support for the development and innovation of the industrial clusters.

Optimization of industrial structure upgrading. First of all, governments at all levels need to pay enough attention to the new strategic industries to develop a blueprint for industrial clusters. This is a long-term project, so the government and various functional departments need to strengthen cooperation to face the shortage of resources and the destruction of the environment, so as to open up a path for the development of new industries. Taking the comprehensive economy,transportation,resources,climate and other factors into account according to local conditions, rational planning and development priorities. Secondly, in the different stages of the development of industrial clusters, we need to make appropriate support 
policies. The development of new industries need to break through the constraints of traditional enterprise development, therefore,we should encourage enterprises who with $R \& D$ strength to initiate research activities independently.

\section{Collaborative Development Strategies for Strategic Emerging Industrial Clusters}

Fully coordinate the relationship between the market and the government. In the process of market development, due to its own characteristics, it is easy to be affected by a variety of objective factors, which requires the government and market mechanisms to regulate and control. Once the market problems, the government needs to take macro-control measures to intervene in order to maintain the stability of the market economy. With the changes in market structure and other factors, the corresponding should change in macroeconomic regulation and control means. In the process of the development of strategic emerging industries, the external objective factors have a great obstacle to it, and it is unrealistic to rely entirely on its own regulation and macro-control of the government, so the benefit sharing and innovation driven is the driving force for sustainable development of strategic emerging industrial clusters. In order to achieve healthy and sustainable development,it requires the coordination and management of the government to ensure the persistence of this linkage effect. Therefore, it is necessary to give full play to the leading role of strategic emerging industries in the development of other industries .The linkage between strategic emerging industries will be able to play a important role on the development of industrial clusters.

Strengthen the innovation ability of industrial clusters. The development of the industry is inseparable from the driving force of innovation, only continuous innovation can enhance the market competitiveness of enterprises and occupy a larger market share in the fierce market competition. For the existing problems, it needs to change ideas and methods in time,to strengthen scientific research, to add scientific and technological content to products to promote the development of strategic emerging industrial clusters. In order to develop the platform of knowledge network tools and make it suitable for its application, to establish a system of knowledge, technology and talent database for industrial clusters, to provide professional knowledge intermediary services for industrial clusters, we will build a first-class industrial cluster knowledge network system. At the same time, we will provide preference and support for the industrial cluster technological innovation from the government and financial institutions level, especially for the independent innovation and cooperative innovation. What's more, we will encourage enterprises' development and knowledge trading so that to establish a sound incentive mechanism for the innovation behavior of industrial clusters and shape the knowledge culture and innovation culture actively.

Optimize the development environment of industrial clusters. In the process of developing strategic emerging industrial clusters, it is necessary to ensure the orderly implementation of activities, which the inevitable choice to perfect the corresponding system and to promote the investment and financing legislation of strategic emerging industrial clusters. In the long run, the current legal norms can only provide a framework about the investment and financing for strategic emerging industrial clusters, but some contents of investment and financing of monopoly industries also have obvious limitations, such as, a lack of legislation process of industrial investment and financing.Therefore, it is essential to optimize the industrial agglomeration environment, to improve the corresponding system for investment and financing, to provide security and to promote the development of new industrial clusters.

Strengthening the construction of professional quality of industrial clusters. The development process of strategic emerging industrial clusters can not be separated from the construction of talent team, so the establishment of a high-quality talent team will help stimulate 
industrial innovation and enhance market competitiveness. Because of high content of science and technology in the strategic emerging industrial clusters, a large number of high-tech talents are urgently needed in the development process. Through the cooperation and communication between enterprises and high schools, it can give full play to the advantages of intensive intelligence. At the same time, enterprises' access will promote the personnel training more in line with the actual needs of the market, so as to meet the needs of the development of strategic emerging industries better. In addition, we should also attach importance to the introduction of talent, improve the living environment and quality of life of the clusters, to attract more talented people to join them, which is a key factor to ensure the maintenance of talent. It is very necessary to strengthen the construction of knowledge infrastructure for the strategic emerging industrial clusters, which is helpful to the communication between the talents and to stimulate creativity.Besides, it also has a profound impact on the technological innovation.

\section{Summary}

China's macro-policy proposed the development of strategic emerging industries. Therefore, it has a positive significance to choose a good development model for the innovation development of strategic emerging industries . This paper puts forward the development path of the value chain, the knowledge chain and the Internet of things as the media, analyzes the meaning and function of these three paths, and provides reference for the future scientific construction and development model. At the same time, it proposes some carrier forms and development strategies of the development of strategic emerging industrial clusters to promote the development of industrial cluster. This paper argues that the innovation development of the strategic emerging industrial clusters will become an effective, stable and far-reaching development model in sustainable development.

\section{References}

[1] Zhu Bin, Ou Weiqiang. Research on the Coordinated Development of Strategic Emerging Industry Clusters Across the Taiwan Strait[J].Scientific Research Management,2016,(07):35-46. [2] Li Jie, Huo Guoqing,Sun Hao. Analysis on Determinants of China's Strategic Emerging Industry Clusters[J]. Scientific and Technological Progress and Countermeasures, 2014,(17):55-60.

[3] Zhang Hongchao, Luo Guoyu. Study on the Magnetic Field Effect of Strategic Emerging Industry Clusters[J]. Science and Technology Management Research,2013,(22):181-184+189.

[4] Wang Qiwan, Wang Xingyuan. Research on Brand Ecosystem of Strategic Emerging Industry Clusters [J]. Scientific Research Management,2013,(10):153-160.

[5] Yu Dengke, Tu Guoping, Chen Hua.Research on the Path and Mode of Strategic Emerging Industry Cluster Collaborative Development [J].Scientific Research Management, 2012,(04):114-120.

[6] Li Yang, Shen Zhiyu. Research on the Innovation and Development of Strategic Emerging Industrial Clusters [J]. Economic and Management Research, 2010,(10):29-34.

[7] Liu Zhiyang, Cheng Haishi. Cluster Cultivation and Network Characteristics of Strategic Emerging Industries [J]. Reform, 2010,(05):36-42. 